\title{
LAS MANCOMUNIDADES EN NUESTRO DERECHO LOCAL: EVOLUCION HISTORICA*
}

\author{
POR \\ TOMÁS QUINTANA LÓPEZ \\ Profesor titular de Derecho Administrativo
}

SUMARIO: A) LAS Mancomunidades en el moderno municipalismo: a) Generalización y uniformidad del régimen municipal; b) Incorporación de las Mancomunidades al régimen municipal.-B) MANCOMUNIDADES Y AGRUPACIONES EN LA LEGISLACIÓN LOCAL PRECEDENTE: a) La Ley de Bases de 1945 y el texto refundido y articulado de 1955; b) Mancomunidades y agrupaciones en la Ley $41 / 1975$ y su texto articulado parcial de 1977: a') Municipales, b') Provinciales; c) Algunas consecuencias derivadas de la aprobación de la Constitución: $a^{\prime}$ ' La intervención gubernativa posconstitucional, b') Principio de autonomía y fines de las Macomunidades, c') Mancomunidades provinciales.

\section{A) LAS MANCOMUNIDADES EN EL MODERNO MUNICIPALISMO a) Generalización y uniformidad del régimen municipal}

La caída del antiguo régimen, presupuesto para la aplicación del Estado contemporáneo, supone también un trascendental hito para la organización municipal de la Europa continental, tal como actualmente se nos presenta. Es sabido que los revolucionarios franceses rechazaron el tipo de municipio heredado del absolutismo, fruto del privilegio, regido, por tanto, mediante normas particulares, dictadas ex profeso, más bien otorgadas con carácter singular (1). El principio de igualdad, aplicado ahora a la organización territorial del nuevo Estado, resulta difícilmente compatible con aquel sistema municipal; en consecuencia, en 1789 se aborda la construcción del nuevo municipalismo mediante dos Decretos, de 14 y 22 de diciembre. A nuestros efectos, este último resulta de particular interés, en cuanto que, frente al orden municipal anterior, discontinuo y alternante con otras formas de organización territorial, supuso la generalización del municipio en todo el territorio francés, «il y aura une municipalité en chaque ville, bourg, paroisse ou communante de campagne». De esta fecha datan los inicialmente 44.000 municipios en Francia, reducidos en la actualidad a $36.000(2)$.

- Este trabajo forma parte de otro más amplio realizado sobre las Mancomunidades y la prestación de servicios por la Administración local, realizado con una ayuda de investigación concedida por el INAP, a quien agradezco las facilidades que me ha dado para su publicación.

(1) Cfr. GARCIA DE ENTERRIA E.: Revolución Francesa y Administración contemporánea, Taurus, Madrid, 1981, p. 100.

(2) Vid. sobre los criterios contrapuestos que se manejaron a la hora de configurar el mapa municipal francés y la fórmula final de instaurar un municipio en cada núcleo de población por pequeño que fuera, en PARADA VÁZQUEZ, J. R.: "Derecho Administrativo (Organización y empleo públicol». Marcial Pons, Madrid, 1987, pp. 79 y ss. 
Nuestro país incorpora el sistema municipal surgido de la Revolución Francesa a la Constitución de Cádiz (3). Su artículo 310 disponía la creación de Ayuntamientos en los pueblos que no lo tuvieran y en los que fuera conveniente su existencia, no pudiendo dejar de haberlos en los que por sí o con su comarca lleguen a 1.000 almas (4). Fácilmente se observa que el constituyente español se aleja de su modelo francés, al preferir, con carácter general, el criterio del número de habitantes frente al territorio manejado en Francia a la hora de generalizar el instituto municipal en el territorio español. La generalización del régimen municipal llega a España con la Constitución de 1812, y éste es, pues, el momento en que se inicia la reacción frente a la variada organización territorial que presentaba nuestro país durante la monarquía borbónica, abocando a un sistema municipal uniforme (5). Generalización y uniformidad desaparecieron con el retorno de Fernando VII; por Real Cédula de 30 de julio de 1814 quedaron disueltos los Ayuntamientos constitucionales y declarado nulo el ordenamiento local postgaditano. El Ilamado Trienio Liberal

(3) Ya el discurso preliminar al Proyecto de Constitución presentado por Argüelles confía a la generalización de los Ayuntamientos en toda la extensión de la Monarquía, bajo reglas fijas y uniformes, que éstos alcancen toda la perfección que pueda desearse. Vid. ADOLFO POSADA "Evolución legislativa del Régimen Local en España, 1812-1909». IEAL, Madrid, 1982, p. 63 También GARCIA FERNÁNDEZ, J.: "El origen del municipio constitucional», IEAL, Madrid, 1983, pp. 260 y 261.

(4) En efecto, este es el número acogido por la Constitución para la creación de Ayuntamientos, sin embargo, lo cierto es que el debate posterior a la presentación del Proyecto evidenció el deseo de algunos intervinientes en el sentido de facultar la constitución de Ayuntamientos en pueblos de menor población; así, el señor Aner se preguntaba: «... qué razón puede haber de utilidad o conveniencia para no decir que haya Ayuntamientos en todos los pueblos aunque no lleguen a 1.000 almas». El apoyo del señor Argüelles era expreso: "La Comisión no se opone a eso. El artículo dice que se pondrá Avuntamiento en los pueblos donde no lo haya y donde convenga. La Comisión lo que quiso prevenir con esto fue el que, no llegando a 1.000 almas un pueblo, no dejase de tener Ayuntamiento. La conveniencia de los pueblos hará que muchos que ahora carecen de Ayuntamiento lo tengan en adelante...) Vid. ADOLFO POSADA: Evolución legislativa..., cit. pp. 73 y 74 . Este clima favorable al establecimiento de municipios sin ajustarse estrictamente a un número determinado de habitantes se puso de manifiesto también en un Decreto de 23 de mayo de 1812, sobre la formación de Ayuntamientos constitucionales, dos meses después de promulgada la Constitución gaditana, al permitir que cualquier pueblo que no tuviese Ayuntamiento y cuya población no llegue a 1.000 habitantes, pero que por sus particulares circunstancias de agricultura, industria o población considere que debe tener Ayuntamiento, lo hará presente a la Diputación de la provincia, para que en virtud de su informe se provea lo conveniente por el Gobierno. La legislación posterior, tomada en consideración por PARADA VÁZOUEZ. Derecho Administrativo..., cit., p. 82, muestra una progresiva reducción del número de personas exigido para la formación o mantenimiento de los municipios, y, como advierte este auto, fue el Real Decreto de 23 de julio de 1835, sobre Arreglo provisional de los Ayuntamientos del Reino, el responsable de que la municipalización de la parte de España caracterizada por la dispersión de su población responda a la mezcla de dos criterios: la territorialidad (cuatro leguas en cuadro) y el número de vecinos.

(5) Tres razones han sido identificadas como impulsoras de este fenómeno: a) Respuesta a la variedad municipal del Antiguo Régimen, b) incardinación del municipio en el poder ejecutivo y control del mismo sobre los municipios, c/ respuesta al federalismo americano y al fuerismo de ciertos Diputados velencianos $y$ catalanes. Vid. GARCiA FERNÁNDEZ, J.: El origen..., cit. pp. 284 y ss. 
(1820-1823), en cuyo período se aprueba la institución para el Gobierno Económico-Político de las Provincias - de 2 de marzo de 1823, no supone una alteración de los principios que inspiraron el municipalismo gaditano, es decir, se mantiene el régimen municipal generalizado y uniforme sobre la base de cuatro pilares fundamentales: Ayuntamientos, Diputaciones Provinciales, Alcaldes y Jefes políticos. Restablecido el absolutismo, hubo que esperar a 1836 para que, bajo la vigencia del Estatuto Real de 1834, por Ley de 15 de octubre, fuera dispuesto el vigor de la Ley de 2 de marzo de 1823, situación que se alarga hasta 1845, año en que fueron aprobados las Leyes municipal y provincial, ambas de 8 de enero. De nuevo, durante el Bienio Progresista, por Decreto de 7 de agosto de 1954, recobraron vigencia la Ley de 3 de febréro de 1823 y demás normas dictadas con anterioridad a 1843, vigencia que se extendió hasta la aprobación de la Ley municipal elaborada en este período, de fecha 5 de julio de 1856. No tardó mucho tiempo en ser derogada; por Real Decreto de 16 de octubre del mismo año fue restablecido nuevamente el imperio de las Leyes municipal y provincial de 8 de enero de 1845.

Del período contemplado hasta ahora, si se exceptúan las épocas de retorno al absolutismo, desde la perspectiva que ahora nos interesa, puede afirmarse que está marcado por la generalización del régimen municipal, es decir, por la organización de todo el territorio español en municipios y provincias y por la dotación de un régimen jurídico uniforme.

\section{b) Incorporación de las mancomunidades al régimen municipal}

El paso de los años descubrió «los graves inconvenientes que ofrecen esas Municipalidades microscópicas", por lo que los redactores del Proyecto de Ley fechado el 2 de noviembre de 1860, y presentado por don José Posada Herrera, acentuaron la tendencia, ya latente en ese momento, hacia la ampliación de la unidad muinicipal mínima, pero, sobre todo, facultaban, mediante aquél, a los municipios que reunieran determinadas características la formación de uniones meramente administrativas (6), que con la

(6) «No es necesario una larga práctica administrativa para conocer los graves inconvenientes que ofrecen esas municipalidades microscópicas, como son muchas de las que hoy existen, y que más bien que agregaciones de carácter público, pueden considerarse como familias dilatadas; sin recursos para cubrir sus más perentorias atenciones; sometidas ciegamente a la influencia del vecino más rico o más astuto o menos ignorante, que la ejerce por lo común en provecho propio; agobiadas con la carga de un presupuesto superior a sus fuerzas, imposibilidades de rodearse, por falta de medios para dotarlos decorosamente, de auxiliares inteligentes-que los ilustren y aconsejan en la gestión de sus negocios y en sus relaciones con sus delegados superiores del Gobierno; estos Ayuntamientos no sólo son una rémora constante 
denominación de comunidades fueron el germen de lo que después habian de ser las Macomunidades (7). La normativa legal surgida de la Revolución de 1868, la Ley municipal de 20 de agosto de 1870 , su artículo 75 , por fin positiviza la autorización para que los Ayuntamientos pudieran formar entre sí y con los inmediatos asociaciones y comunidades para construcción y conservación de caminos, guardería rural, aprovechamientos vecinales y otros objeto de su exclusivo interés; las comunidades habrían de regirse por una Junta, compuesta por un delegado de cada Ayuntamiento y presidida por un vocal elegido por la Junta. La reforma del régimen local practicada durante la primera época de la Restauración borbónica no altera el contenido del precepto citado; el artículo 80 del texto resultante de la inserción en la Ley municipal de 1870 de la Ley de 16 de diciembre de 1876, repite la dicción del artículo 75 que se acaba de transcribir.

Después de la aprobación, en 1882, de la Ley provincial se abre un período en que una y otra vez se acomete la reforma del régimen local. Los Proyectos de Ley se suceden (8), siendo sólo de nuestro interés destacar aquellos aspectos que tienen relación con el objeto de este trabajo (9).

En la línea de lo manifestado en el preámbulo del Proyecto de Ley de 1860, el presentado por Romero Robledo en 1884 hacía hincapié en la conveniencia de suprimir los municipios de escaso vecindario. Algunos años más tarde, don Segismundo Moret presentó otro Proyecto de Ley sobre reforma de la Ley municipal

para la Administración en general, sino incapaces de llenar el objeto propio de una Asociación de su indole. Hace tiempo que la opinión, irrevocablemente pronunciada en este sentido, ha sido acogida, aunque tímidamente, por los legisladores, y el Ministro que tiene la honra de dirigirse al Congreso, al tomar el número de $\mathbf{5 0 0}$ vecinos como tipo mínimo de la "unidad municipal", no hace más que seguir la huella que encontró marcada, y satisfacer con alguna mayor latitud una necesidad de conocida urgencia... Otra innovación se introduce en la materia de que se trata, que extendida y desarrollada convenientemente, puede crecer en importancia y ser el principio de una medida general. Se refiere el Ministerio que suscribe a la facultad de formar uniones meramente administrativas bajo el nombre de "Comunidades", concedida a los Ayuntamientos que reúnen ciertas circunstancias. Este género de Asociación, en lo relativo principalmente al disfrute de los aprovechamientos comunes, tiene numerosos precedentes en la historia patria, y ha llegado hasta nuestros días con la denominación de "Universidades, Hermandades" y otras semejantes." El texto transcrito se corresponde con algunos párrafos del preámbulo del Proyecto de Ley de 1860, sobre Organización y Atribuciones de los Ayuntamientos.

(7) Como se ha recordado recientemente, un antecedente más remoto de las actuales mancomunidades se encuentra en las asociaciones o convenios, existentes desde el medievo, tanto para fines militares y políticos como económicos. Vid. MARTín MATEO, R.: «Entes Locales complejos», Trivium, Madrid, 1987, pp. 46 y 47; también, SOSA WAGNER, F.: «Mancomunidades y otras formas asociativas». Tratado de Derecho Municipal I, obra colectiva dirigida por MUÑOZ MACHADO, S., Civitas, Madrid, 1988, p. 1041.

(8) Vid., una recopilación de ellos junto a la normativa local propiamente dicha en: COSCULlUELA MONTANER, L., y ORDUÑA REBOLLO, E.: "Legislación sobre Administración Local 1900-1975", IEAL, Madrid, 1981.

(9) Para una visión general de las tendencias que guian la frustrada reforma.del Régimen Local en esta época, vid., ADOLFO POSADA: Evolución legislativa, cit., pp. 375 y ss. 
en el que se preveía la formación por los Ayuntamientos de uniones para la prestación de ciertos servicios, de constitución en general voluntaria, excepto en ciertos casos en que serian obligatorios; este mismo Proyecto de Ley parece identificar las uniones a que se ha hecho referencia con las mancomunidades, por vez primera expresamente citadas, si bien a ellas se refiere de forma específica para obligar su formación cuando el Gobierno subvencione obras públicas que interesen a diversos pueblos; también admite la mancomunación de dos provincias contiguas. No había pasado aún un año y don Antonio Maura presentó otro Proyecto de Ley y Bases para la reforma de la Administración local (26 de mayo de 1903); en él se contemplaba la forzosa unión o mancomunidad de municipios incompletos (menos de 2.000 residentes) para la gestión de asuntos de interés para todos ellos; voluntariamente, los Ayuntamientos de más de 2.000 residentes también podrían formar uniones municipales o mancomunidades para el cumplimiento de fines administrativos de interés común. El 3 de febrero de 1906, el Conde de Romanones presentó al Congreso de los Diputados un nuevo Proyecto de Ley de Bases para la reforma de la Ley municipal; además de la elevación del número de habitantes hasta 8.000 exigido para la formación obligatoria de uniones o mancomunidades a fin de atender ciertos servicios, la novedad más destacable de este Proyecto de Ley es la posibilidad que ofrece a los Ayuntamientos integrantes de uniones voluntarias -por tanto, con más de 8.000 habitantes- de pedir la exención parcial del régimen provincial y de dependencia de las Diputaciones, prestando ellas directamente los servicios confiados a éstas. El año siguiente, el 31 de mayo, el Ministro de Gobernación, don Juan de la Cierva, presentó un nuevo Proyecto de Ley sobre Régimen de la Administración local; en él también se presta atención a las mancomunidades, configurándolas de dos tipos: Municipales $y$ provinciales; a las primeras se referían los artículos 25 y ss., distinguiendo las asociaciones de municipios creadas para fines $o$ servicios comunes de competencia municipal, de las también consideradas mancomunidades, uniones de municipios constituidas para prestar servicios del Estado; las segundas, las provinciales, se formarían a partir de dos o más provincias, para gestionar fines o servicio de competencia de las Diputaciones, siendo, en la idea del legislador, el embrión de futuras regiones (10). El último intento de reforma del régimen local anterior a los Estatutos de la Dictadura de Primo de Rivera se materializó en un Proyecto de Ley de Bases sobre régimen local presentado al Congreso por don Antonio Barroso y Castillo el 15 de octubre de 1912; con él se

(10) Cfr. Adolfo POSADA: Evolución legislativa..., cit., p. 467. 
pretendía facultar a los municipios para mancomunarse o asociarse con el objeto de atender al cumplimiento de fines o servicios comunes, o bien de gestionar los servicios y obras públicas de interés para sus respectivos términos municipales, aun tratándose de materias no comprendidas en su competencia. Se abría, igualmente, la posibilidad al Gobierno de disponer la unión de municipios limítrofes de menos de 2.000 habitantes para el ejercicio de funciones que no fueran de la exclusiva competencia municipal, es decir, aquellas que las autoridades locales actuaran por delegación del poder central.

La revisión del ordenamiento local que se realiza durante el Directorio Militar a través de los Estatutos Municipal y Provincial de 1924 y 1925, fiel a la tradición marcada por los Proyectos de Ley precedentes, reconoce -artículos 6 y ss. del Estatuto Municipala los municipios la posibilidad de mancomunarse libremente, aunque pertenezcan a provincias o regiones distintas, tanto para cumplir fines, servicios y otras de la competencia municipal, como para solicitar y explotar concesiones o servicios públicos, sean o no de responsabilidad del municipio. Aparecen ahora también por primera vez, como herederas de las uniones de municipios, las agrupaciones de éstos, cuando sean limítrofes y cuenten con menos de 2.000 habitantes, con objeto de que cumplan servicios y funciones que no sean de la exclusiva competencia municipal y las autoridades locales actúen por delegación del Gobierno o Administración del Estado. También el Estatuto Provincial -artículos 18 y ss.- permite a las Diputaciones Provinciales agruparse en mancomunidades de carácter administrativo para la ejecución de obras o prestación de servicios de su competencia y de carácter interprovincial.

La legislación local de la II República -Ley municipal de 31 de octubre de 1935-, si se exceptúa la distinta nomenclatura que utiliza, pocas novedades introduce en este tema. En efecto, los artículos 23 y ss. se permiten que los municipios, limítrofes o no, aún pertenecientes a provincias distintas, puedan agruparse para realizar fines, obras o servicios comprendidos dentro de las competencias municipales. o que, aun excediendo de éstas, interesen conjuntamente a varios términos. Al lado de estas agrupaciones voluntarias, el artículo 27 remitió a la Ley la constitución de agrupaciones forzosas de municipios limítrofes para la realización de servicios obligatorios, sean de la titularidad municipal o delegados de la Administración central. Del contenido de los artículos que siguen al que acaba de citarse, parece deducirse que la intención del legislador fue circunscribir la formación de agrupaciones forzosas de municipios a aquellos supuestos en que los Ayuntamientos 
aisladamente pudieran cumplir los servicios legalmente considerados como obligatorios.

Durante la II República, Cataluña también aprobó su propia Ley municipal, incluso antes que la estatal, concretamente el 14 de agosto de 1933. No faltaron en ella disposiciones relativas al tema que aquí se trata, de forma que, bajo la denominación de asociaciones de municipios, los artículos 16 y ss. disponían dos tipos de asociaciones: Las voluntarias, para cumplir los fines que la Ley asignaba a los municipios, y las obligatorias, para el sostenimiento en común de un Secretario, siempre que concurrieran determinadas circunstancias.

\section{B) MANCOMUNIDADES Y AGRUPACIONES EN LA LEGISLACION LOCAL PRECEDENTE}

\section{a) La Ley de Bases de 1945 y texto refundido y articulado en 1955}

La escasa proliferación de las mancomunidades a lo largo del dilatado período de tiempo considerado en las últimas páginas (11) no fue óbice para que el ordenamiento local consolidado a partir de 1945 recibiera estas fórmulas asociativas locales (12) objeto de nuestra atención (13).

(11) En un trabajo publicado en los números 27 y 28 de la REVL en el año 1946, bajo el título «Las Mancomunidades Municipales», HERNÁNDEZ RUIZ, R., funcionario local y, por tanto, conocedor de estos temas, se preguntaba por las razones de que los municipios prescindieran de las Mancomunidades $y$-agrupaciones, encontrando la explicación en el acentuado individualismo, apego a los viejos moldes y a la rutina, antiguas rivalidades, resquemores y pugnas personales, p. 389.

(12) La regulación de las Mancomunidades y agrupaciones, como se verá seguidamente, a partir de 1955 está contenida en los artículos 29 y ss. del texto articulado y refundido sobre el régimen local de ese año, siendo derogados posteriormente por los artículos 18 y ss. del texto articulado parcial de la Ley $41 / 1975$. No obstante ser ésta la regulación general sobre Mancomunidades, lo cierto es que tanto el texto de 1955 como otras normas contenían preceptos referidos a específicos tipos de Mancomunidades; así, sin entrar en todos los sectores donde estaban o, incluso, está prevista su constitución, el artículo 139 se ocupaba de las Mancomunidades creadas por municipios colindantes para formular y ejecutar conjuntamente proyectos de urbanización; también el derogado Reglamento de Organización, Funcionamiento y Régimen Jurídico de las Corporaciones Locales, aprobado por Decreto de 17 de mayo de 1952, regulaba en sus artículos 427 y ss. las Mancomunidades interinsulares; sobre ellas, Vid. VALLE BENITEZ J., "Las mancomunidades interinsulares canarias y los servicios municipales", "XIV Congreso Interamericano de Municipio...". Málaga, 1972, IEAL, Madrid, 1973, pp. 1181 y ss. En el sector de urbanismo también han sido previstas las Mancomunidades y agrupaciones forzosas de municipios (artículos 216 de la Ley del Suelo, texto refundido en 1976, y artículos 9 y ss. del Reglamento de Gestión Urbanística).

(13) También el Proyecto del Código de Gobierno y Administración, elaborado en 1941. siendo Ministro de Gobernación Serrano Súñer, preveía que los municipios pudieran Mancomunarse voluntariamente 0 , incluso, ser obligados a ello con objeto de elaborar y ejecutar un proyecto de urbanización conjunta (antecedentes de las posteriores mancomunidades urbanisticas) o de coordinación de servicios. 
Con el soporte proporcionado por la base III de la Ley de Bases de Régimen Local de 17 de julio de 1945, los artículos 29 y ss. del texto articulado y refundido aprobado por Decreto de 24 de junio de 1955 (14) regularon las mancomunidades voluntarias y agrupaciones forzosas. Las primeras, de libre formación por los municipios, tenian por objeto la realización de obras, servicios y otros fines de la competencia municipal; dotadas de capacidad juridica para el cumplimiento de éstos, su régimen se remite a los Estatutos y Ordenanzas, aprobados inicialmente por los Ayuntamientos mancomunados y sometidos después a la aprobación del Consejo de Ministros, previo dictamen del Consejo de Estado. Esto último hace imprescindible tener en cuenta la doctrina del alto cuerpo consultivo si se pretende analizar la aplicación real de los preceptos reguladores de las mancomunidades; un somero repaso de la misma nos muestra una serie de cuestiones sobre las que reiteradamente se pronuncia el Consejo de Estado, consolidando una doctrina (15), de la que nos hacemos eco parcialmente a continuación.

(14) VID. un comentario a los mismos en MARTiN REtoRTILLO, C.: Ley de Régimen Local (texto refundido de 1855), Aguilar, Madrid, 1958, pp. 24 y ss.

(15) Es muy ilustrativa la completa doctrina desarrollada por el Consejo de Estado en su dictamen de 16 de marzo de 1967 (exp. núm. 35.362); en él resuelve los aspectos más sustanciales de las mancomunidades como seguidamente se transcribe:

\section{«I. NATURALEZA JURIDICA DE LAS MANCOMUNIDADES.}

El artículo 10 de la Ley de Régimen Local enumera como Entidades Municipales:

a) El Municipio.

b) La Entidad Local Menor.

c) La Mancomunidad municipal voluntaria.

d) La Agrupación municipal forzosa.

Concuerda con este precepto el artículo $1 .^{\circ}$ del Reglamento de Población y Demarcación Territorial de las Entidades Locales.

A tenor de ellos, la Mancomunidad resulta una especie dentro del género de "Entidades Municipales", por lo que les corresponde la naturaleza propia de éstas. Dentro de ellas, en lugar de caracterizarse, como el Municipio propiamente dicho o la Entidad Local Menor, como entes de competencia territorial, con potestades diversas para la administración de intereses en sus territorios, las Mancomunidades y agrupaciones forzosas se configuran como Entidades superpuestas a esas de carácter territorial, que abarcan dos o más de ellas, con competencias especificas relativas a los fines peculiares que las son propias

Congruentemente, el artículo 32 de la propia Ley atribuye a las Mancomunidades plena capacidad jurídica para el cumplimiento de sus fines, correspondiendo su representación a los Organismos designados estaturariamente. Es dudosa, en cambio, esa atribución de perisonalidad a las Agrupaciones forzosas, en contra de la cual se pronunció la Sentencia del Tribunal Supremo de 5 de octubre de 1932.

Son pues características de las Mancomunidades:

a) La voluntariedad.

b) La competencia específica, extendida a más de un Municipio o Entidad Local.

c) La personalidad juridica.

d) La naturaleza de Entidades Municipales

\section{ELEMENTOS SUBJETIVOS}

Indiscutible, por esencia, la posibilidad de que entren a formar parte de las Mancomunidades los Municipios, parece preciso, asimismo, admitir que pueden integrarse en ellas Diputaciones 


\section{El propio órgano consultivo define lo que considera sus funcio-} nes, que identifica con la ilustración al Gobierno para su decisión, sobre los siguientes aspectos: Si el objeto de la mancomunidad que

y Entidades Locales Menores, problema sobre el que el Consejo de Estado no se extiende en este dictamen, por ajeno a él y por haberlo hecho en otras ocasiones, en que quedó clara su doctrina sobre el particular.

El artículo 30 de la Ley de Régimen Local y el 54 del Reglamento de Población y Demarcación permitan la Mancomunidad aun en el caso de Municipios no limítrofes o de provincia distinta.

Compete al pleno de las Corporaciones según los artículos 121, b), y 270, a), de la Ley, la constitución, modificación o disolución de Mancomunidades.

\section{ELEMENTOS OBJETIVOS}

El artículo 29 de la propia Ley de Régimen Local establece que "los Municipios podrán formar Mancomunidades para obras, servicios y otros fines de la competencia municipal", precepto con el que concuerda el artículo 53 del Reglamento de Población y Demarcación. La enumeración de estos fines es la del artículo 101 de la Ley.

\section{ELEMENTOS FORMALES}

Por su parte, el artículo 33 de la Ley dispone que "el acuerdo de constitución en Mancomunidad ha de ser tomado en cada Ayuntamiento con el quórum señalado en el artículo 303. Cada uno de los Ayuntamientos interesados designará un representante de la Comisión que haya de redactar los Estatutos de la Mancomunidad, los cuales habrán de ser ratificados por las Corporaciones respectivas"; a lo que el Reglamento de Población y Demarcación añade que la ratificación ha de hacerse en sesión extraordinaria. El trámite de aprobación de los Estatutos se regula en el artículo 34 de la Ley, que dispone que tanto ellos como las Ordenanzas de su régimen que hubieran obtenido la aprobación de todos los Ayuntamientos afectados serán sometidos a la del Consejo de Ministros, por conducto del de la Gobernación, previo dictamen del Consejo de Estado; a lo que adiciona el artículo $5^{\circ}$ del Reglamento de Población la exigencia del informe de la Comisión Provincial de Servicios Técnicos, debiendo el Gobierno Civil elevarlos al Ministerio de la Gobernación en el plazo de treinta dias.

Para la aprobación por el Gobierno de los Estatutos y Ordenanzas otorga el artículo 35 de la Ley un plazo de tres meses, contados desde la fecha de recepción del proyecto por el Ministerio de la Gobernación. Transcurrido ese plazo sin que recaiga acuerdo, se considerarán aprobados, es decir, que se considera el silencio como trámite de aprobación.

\section{CONTENIDO DE LOS ESTATUTOS.}

El artículo 37 de la Ley señala como extremos de obligatoria inclusión en los Estatutos:

a) Los Municipios que comprende la Mancomunidad.

b) Lugar en que radiquen sus órganos de administración.

c) Número y forma de designación de los Concejales que han de integrar la Comisión gestora.

d) Fines de la Mancomunidad.

e) Recursos económicos.

f) Plazo de vigencia.

g) Procedimiento de modificación de Estatutos.

h) Casos de disolución.

Esta enumeración se reproduce y completa en los artículos 32 (órganos representativos) y en los 61, 62 y 64 del Reglamento de Población (incorporación o separación de Municipios. Comisión gestora, etc.).

\section{ANALISIS DEL EXPEDIENTE A LA LUZ DE ESTA NORMATIVA.}

La misión del Consejo de Estado en su dictamen consiste en ilustrar al Gobierno, a quien incumbe la aprobación o denegación de ella con respecto a los Estatutos de la Mancomunidad, sobre los siguientes extremos:

REVISTA DE ESTUDIOS. -4 
se pretende crear se circunscribe a la realización de obras, servicios y otros fines de la competencia municipal; si la tramitación del expediente fue o no correcta; si existen extralimitaciones legales en los Estatutos (16). Por su parte, el Gobierno, en la consideración de la doctrina del Consejo de Estado, no podrá introducir modificaciones en los Estatutos, limitándose sólo a otorgar o denegar la aprobación, indicando, en su caso, las extralimitaciones legales que deban corregirse o las normas de interés general que proceda tener en cuenta (17). Este último parámetro tenía su origen en el artículo 59.3 del Reglamento de Población y Demarcación Territorial de las Entidades Locales de 17 de mayo de 1952 y fue objeto de una flexible interpretación por el Consejo de Estado, en el sentido de que dicho precepto, al no concretar lo que debe entenderse por normas de interés general, facultaba al Gobierno para considerar con este carácter cualquier tipo de norma, y no sólo las estrictamente legales (18). Evidentemente, una interpretación como ésta ponía en las manos del Gobierno un importante instrumento de control de las futuras mancomunidades.

Por lo que tiene de testimonial, merece la pena destacar un criterio reiterado por el Consejo de Estado sobre la interpretación de los artículos 37 y 62 , respectivamente, del texto articulado y refundido de 1955 y el Reglamento de Población del 52. Este alto órgano consultivo parte de que "tanto el artículo 37 de la Ley como el 62 del Reglamento de Población y Demarcación Territorial son terminantes en la exigencia de que los miembros de las Comisiones gestoras de las mancomunidades sean precisamente Concejales de los Ayuntamientos mancomunados», por lo que "aun cuando no existe obstáculo legal que se oponga a que el Concejal del Ayuntamiento, durante el período de su mandato, puede reunir a la vez la condición de Alcalde, su título para integrar o formar parte de la Comisión gestora de una mancomunidad se debe, a juicio del Consejo de Estado, al hecho de ostentar el primero de los cargos mencionados, y no al segundo. La diferencia es importante, ya que no puede olvidarse la distinta naturaleza de uno y otro cargo, tal

a) Si la Mancomunidad versa sobre «obras, servicios y otros fines de la competencia municipal», lo que parece evidente en el presente caso.

b) Si la tramitación del expediente fue correcta, lo que en el caso consultado resulta de la observancia de los trámites establecidos. Sin embargo, deberá certificarse, sobre la concurrencia o no del quórum legal en los acuerdos de los Ayuntamientos de $X$ y $Z$., de rectificación de Estatutos.

c) Si existen en los Estatutos «extralimitaciones legales», lo que no se aprecia en los que se informan (artículo 35.2 de la Ley).

d) Las normas de interés general que proceda tener en cuenta (artículo 59.3 del Reglamento de la Población y Demarcación).

(16) Vid., dictamen de 7 de enero de 1966 (Exp. núm. 34.471).

(17) Vid., dictamen de 22 de junio de 1967 (Exp. núm. 35.485).

(18) Dictamen de 7 de enero de 1966 (Exp. núm. 34.471). 
como se configuran legalmente, puesto que la duración del cargo de Alcalde es indefinida y la designación es libre, mientras que el cargo de Concejal es de duración limitada a seis años y su designación electiva» (19). La voluntad del Consejo de Estado de interpretar los preceptos citados de forma favorable a la democratización de las mancomunidades parece clara.

El Consejo de Ministros, habilitado por el artículo 38 del texto articulado de 1955, podía disponer, además de los casos que preveía el artículo 343 de esta norma -referido a la obligación de ciertos municipios de agruparse para sostener un Secretario común-, la agrupación forzosa de municipios para la ejecución de obras públicas subvencionadas por el Estado o para la prestación de servicios obligatorios que fueran de la competencia municipal o delegados de la Administración central. Las diferencias entre las mancomunidades y las agrupaciones forzosas fueron sistematizadas por Bermejo Gironés (20) de la siguiente forma:

a) Las voluntarias se forman por libre acuerdo de los municipios; las forzosas, por imposición gubernativa; por movimiento espontáneo, de abajo a arriba, las primeras; por el inverso, artificial, de arriba a abajo, las segundas;

b) En las agrupaciones forzosas los municipios han de ser limítrofes, $y$ en las voluntarias pueden no serlo $y$ aun pertenecer a provincias distintas;

c) El condicionamiento de las forzosas son los servicios públicos obligatorios, mientras que en las agrupaciones voluntarias o mancomunidades cabe cualquier clase de fines, con tal de que interesen a varios términos $y$ no excedan de la competencia municipal, $y$

d) Las mancomunidades tienen reconocida plena capacidad jurídica para el cumplimiento de sus fines, y las agrupaciones forzosas no, ni tampoco la necesitan, prácticamente, al no surgir con su formación ente nuevo.

\section{b) Mancomunidades y agrupaciones en la Ley 41/1975 y su texto articulado parcial de 1977}

\section{a') Municipales}

La base 13 de la Ley de Bases del Estatuto de Régimen Local de 19 de noviembre de 1975 igualmente previó tanto la mancomunicación voluntaria de municipio como la agrupación forzosa de los

(19) Dictamen de 11 de julio de 1974 (Exp. núm. 39.246).

(20) BERMEJO GIRONÉS. J. I.: "La Mancomunidad Municipal en el despliegue asociativo", XIV Congreso Internacional de Municipios..., cit., pp. 1043 y 1044. 
mismos. En su desarrollo fueron redactados los artículos 10 y ss. del Real Decreto 3046/1977, de 6 de octubre (21). A las mancomunidades municipales, nacidas de la voluntad de los entes integrantes, expresamente se les veta asumir la totalidad de las competencias asignadas a los respectivos municipios; la aprobación definitiva de los acuerdos de constitución y Estatutos, una vez aprobados en sede municipal, correspondía al Consejo de Ministros, previa propuesta del Ministro del Interior y dictamen del Consejo de Estado. Oídos los municipios afectados, la Diputación Provincial y dictamen del Consejo de Estado, el Consejo de Ministros podía imponer la agrupación forzosa de municipios, incluso no limítrofes, para la ejecución de obras y servicios subvencionados o delegados por el Estado.

\section{b') Provinciales}

La mancomunicación de provincias, al menos en grado de tentativa, tampoco ha estado ausente del ordenamiento local. Como ya se ha indicado anteriormente, el Proyecto de 1907 ya contemplaba su constitución, pero hubo que esperar hasta 1913 para que fuera autorizada la creación de mancomunidades provinciales, lo que fue aprovechado en Cataluña para formar una mancomunidad de carácter general, embrión de la futura Generalitat (22). Más tarde, ya en el período que ahora analizamos, como nos recuerda Martín Mateo (23), el Decreto de 15 de junio de 1972, aprobatorio del texto refundido de la Ley del III Plan de Desarrollo, en su artículo 37 posibilitó que las Diputaciones Provinciales y Cabildos insulares se mancomunasen para la realización de acciones conjuntas de desarrollo regional e interprovincial (24).

(21) Con apoyo en la base 11 de la Ley 41/1975, los artículos 1 y ss. de su texto articulado parcial regulaban las agrupaciones forzosas de muncipios con población inferior a 5.000 habitantes.

(22) Martin Mateo, R.: Entes Locales Complejos..., cit. pp. 50 y 51.

(23) MARTín MATEO, R.: Entes Locales Complejos..., cit. p. 51.

(24) Con anterioridad, el Consejo de Estado venia manteniendo que las Diputaciones pudieran participar en las Mancomunidades Municipales, pues, a su entender, no existía precepto legal o reglamentario que lo prohibiera, y, además, la esfera de competencias de las Mancomunidades podia coincidir con la de las Diputaciones. Vid., por ejemplo. Dictámenes de 17 de diciembre de 1970 (exp. núm. 37.292), y de 29 de abril de 1971 (exp. núm. 37.550). Esta doctrina, sin embargo, ha sido corregida con posterioridad; en tal sentido se pronunció el Consejo de Estado en 1982, al afirmar que: El amplio número de Municipios que se asocian, unido al carácter abierto de la Mancomunidad, cara a otros posibles Municipios participantes, hacen esperar importantes logros que repercutirán también de seguro a nivel provincial. Sin duda, por ello, la iniciativa ha sido fomentada por las instancias provinciales tanto por la Administración periférica del Estado como por la Diputación Provincial, aunando esta última sus esfuerzos a la promoción de la nueva entidad. No obstante, la participación de la Diputación se limita a una función de promoción, lo cual es lógico, pues otra cosa sería participar de lleno en los fines de la Mancomunidad, lo que en puridad, habría hecho necesario otra figura organizativa más cercana a los Consorcios, al tratarse de Entes de distinta naturaleza. En esta línea, parece acertada al Consejo de Estado la sugerencia de la Comisión Provincial de Colaboración del 
La Ley de Bases del Estatuto de Régimen Local de 1975, en su base 20, previó las mancomunidades voluntarias de provincias; con el respaldo proporcionado por ella, su texto articulado parcial de 1977 dedicó a su desarrollo los artículos 18 y siguientes. Poco se diferencia el contenido de estos preceptos respecto a los que este mismo texto dedica a las mancomunidades municipales; tampoco las provincias podían asumir la totalidad de las competencias asignadas a las Diputaciones integrantes; también dotadas de personalidad jurídica, su régimen se remite a sus Estatutos, proyectados por las Diputaciones y aprobados por el Consejo de Ministros, previos diversos informes, entre los que destaca el dictamen del Consejo de Estado. La diferencia fundamental entre aquéllas y éstas, además de la relativa a los entes locales que integran una y otra, se encontraba en el objeto que podía ser encomendado; en su caso, las municipales, limitado al cumplimiento de fines de su peculiar competencia, y en el otro, las provinciales, no sólo éstos, es decir, los propios de su competencia, sino también otros encomendados por las distintas Administraciones públicas.

\section{c) Algunas consecuencias derivadas de la aprobación de la Constitución}

El último período de vigencia de la normativa anterior a la reforma de nuestro régimen local producida en 1985, exige matizar algunos aspectos de la aplicación que de la regulación sobre mancomunidades se realizó; obviamente el factor determinante fue la aprobación del texto constitucional en 1978. La influencia de la Constitución en este tema una veces se produjo a través del cambio legislativo y en otros la inserción de los postulados constitucionales en el ordenamiento anterior exigió la labor interpretativa de los tribunales o del Consejo de Estado, pieza ésta, como se ha visto, capital en relación con las mancomunidades.

Ya el Real Decreto-ley 3/1981, de 16 de enero (transformado en lo sustancial en la Ley $40 / 1981$, de 28 de octubre), redactado, según confesó su propia exposición de motivos, para abordar con carácter inmediato algunos problemas y cuestiones que demanda-

\footnotetext{
Estado con las Entidades Locales, al determinar que entre los futuros participantes de la Mancomunidad no pueden estar ni las Entidades Locales Menores ni las Cámaras o Corporaciones de otra índole, pues su presencia en la Mancomunidad desnaturalizaría este tipo organizativo que, desde el punto de vista legal -artículos 10 y ss. del Decreto 3046/1977, de 6 de octubreva referido a la colaboración intermunicipal. (Dictamen núm. 43.969, de 11 de febrero de 1982.) La doctrina mantenida en este último dictamen está de acuerdo con la crítica que MARTíN MATEO ha realizado sobre la sostenida en los dictámenes citados inmediatamente antes, siempre, claro está, sobre la base de la legislación que en estos momentos estamos analizando; vid. MARTIN MATEO: Entes Locales Complejos...., cit., p. 54.
} 
ban una solución urgente, modificó las mayorías exigidas tanto por el artículo 303 de la vieja Ley de Régimen Local de 1955 y, en el mismo sentido, por el artículo 13 del texto articulado parcial de 1977, para acordar la constitución de las mancomunidades y la aprobación de sus Estatutos; en efecto, el artículo 3.2 del citado Real Decreto dejó de exigir el voto favorable de los dos tercios de miembros de hecho del Ayuntamiento, y, en todo caso, la mayoría absoluta legal de sus componentes, para únicamente imponer la necesidad del voto favorable de la mayoría absoluta legal de miembros de la Corporación, tanto para la creación y separación de miembros de una mancomunidad como para la aprobación y modificación de sus Estatutos.

\section{a') La intervención gubernativa posconstitucional}

Se acaba de adelantar la influencia que la aprobación del texto constitucional tuvo la normativa de régimen local, pues bien, ésta se hace más intensa una vez que el Tribunal Constitucional tamizó aquélla a través de las disposiciones constitucionales. Ello obliga a tomar en consideración la doctrina de este alto órgano $y$, en concreto, al ocuparnos de las mancomunidades, la sentencia de fecha 2 de febrero de 1981. A nuestros efectos, tiene especial importancia el fundamento jurídico número 7 , cuyo contenido transcribo a continuación:

"Los artículos 13.3 y 15 del texto articulado parcial de la Ley de Bases del Estatuto de Régimen Local, aprobado por Real Decreto 3046/1977, de 6 de octubre, establecen la competencia del Gobierno para la aprobación de la constitución y Estatutos de las mancomunidades municipales, y asimismo respecto a la disolución por razones de orden público y de seguridad nacional.

A continuación se examina separadamente cada una de las competencias.

Para decidir acerca de la competencia relativa a la aprobación de la constitución y Estatutos, ha de tomarse en consideración lo dispuesto por el artículo 10 del propio texto, el cual dispone que la mancomunidad ha de tener por objeto el establecimiento y desarrollo de obras, servicios y otros fines propios de la competencia peculiar de los municipios. En consecuencia, dada la naturaleza de los fines de la mancomunidad, debe afirmarse que el artículo 15.2 impugnado se opone a la Constitución en cuanto establece un control de oportunidad genérico, al otorgar al Gobierno la competencia para denegar la aprobación de los Estatutos 
por razones de interés público. En cambio, de acuerdo con las consideraciones generales efectuadas en el epígrafe 3 de esta sentencia, no puede entenderse que se oponga a la Constitución el control de legalidad previsto en el artículo 13.3 y resto del 15; por lo demás, en caso de disconformidad con la decisión del Gobierno, cabrá interponer el correspondiente recurso.

En cuanto a la competencia en materia de disolución, tampoco puede afirmarse que se oponga a la Constitución, ya que se otorga con carácter excepcional y en base a la concurrencia de razones de orden público o de seguridad nacional, es decir, por incidir la mancomunidad en el ámbito de intereses generales distintos de los municipios.»

Como resulta del texto transcrito, el control de oportunidad queda excluido de las facultades que reconocía al Gobierno de la Nación el artículo 15.2 del texto articulado parcial de la Ley 41/1975 para decidir acerca de la constitución de mancomunidades y de la aprobación de sus Estatutos (25).

Reconocidas las potestades gubernativas de control tal como ha quedado reflejado, surge otra cuestión íntimamente conectada con ella: algunos Estatutos de Autonomía recibieron competencias, asumieron competencias en materia de régimen local, $y$, además, los órganos administrativos fueron habilitados para el ejercicio de las correspondientes funciones a través de los preceptivos Decretos de transferencias; cuando estos presupuestos se producían, era inevitable plantearse si el control gubernamental a que nos hemos referido y que el Tribunal Constitucional había declarado ajustado a la Constitución, podría o no ser ejercido por el supremo órgano ejecutivo de la Comunidad Autónoma. El interrogante que acaba de ser expuesto fue recientemente resuelto por el Tribunal Supremo en una sentencia de 15 de julio de 1988. (Art. núm. $5901)$ al ser impugnado por el Abogado del Estado un acuerdo de la Generalidad catalana de 20 de marzo de 1986 aprobatorio de la constitución de una mancomunidad. Nótese que la fecha del acuerdo es posterior a la aprobación de la Ley Reguladora de las Bases del Régimen Local, de 2 de abril de 1985, y, sin embargo, el Alto Tribunal opta por entender que no es aplicable el artículo 44 de la misma (26).

(25) En este mismo santido vid. el coetáneo dictamen del Consejo de Estado de 26 de febrero de 1981, exp. 43.155

(26) El razonamiento que utiliza es el siguiente: «... el artículo 44 de la Ley 7/1985, de 2 de abril -que por otra parte no puede decirse que se haya privado a las Comunidades Autónomas que las tuvieran de sus competencias al particular, cuando el artículo mismo defirió a ellas la determinación del procedimiento correspondiente, el que perfectamente podría 
Salvada esta cuestión, referida a la aplicación en el tiempo de las normas jurídicas, surge la que realmente nos ha llevado hasta esta sentencia, es decir, si una vez aprobada la Constitución y los Estatutos de Autonomía, e iniciado el proceso transferencias en favor de las Comunidades Autónomas, las que resultaran competentes en materia de régimen local, dispondrían de la habilitación suficiente para ejercer el control gubernativo de legalidad previo a la constitución de una mancomunidad o a la aprobación de sus Estatutos, cuestión que esta sentencia resuelve en sentido favorable a la conservación interina de dicha facultad por la Generalidad de Cataluña, y ello sobre la base que le proporcionan el Real Decreto de transferencias $2115 / 1978$, de 26 de julio, y el artículo 9.8 y disposición transitoria 6.6 del Estatuto de Autonomía, al permitir a aquélla ejercer las competencias de control, antes depositadas en el Gobierno de la Nación y, posteriormente, como consecuencia de estas normas, transferidas a los órganos autonómicos, al menos hasta que la propia Comunidad Autónoma catalana, en ejercicio de sus competencias legislativas y con los límites surgidos de la legislación estatal básica, dispusiera un procedimiento específico para la constitución de mancomunidades y aprobación de sus Estatutos. Estatal o autonómica, la intervención gubernativa de control de la legalidad en el proceso de formación de las mancomunidades encontró respaldo en la doctrina del Tribunal Constitucional.

Fórmula análoga de control recogía el antiguo Reglamento de Población y Demarcación de 1952 para la adhesión de nuevos municipios a una mancomunidad ya constituida o para la separación de alguno de los integrantes. la intervención gubernativa se materializaba en la aprobación, primero por el Ministro de Gobernación y después por el titular de Administración Territorial; precisamente en relación con la última, es decir la separación de un municipio de la mancomunidad a que pertenecía suscitó la suspensión de ésta por parte del órgano de gobierno de la mancomunidad, finalizando con el planteamiento de un recurso contencioso-administrativo frente a dicha suspensión por parte del municipio secesionista, recurso al que puso fin la sentencia de la Sala de lo

comprender una fiscalización de la legalidad, admitida por la Sentencia del Tribunal Constitucional de 2 de febrero de 1981 - en virtud del principio de irretroactividad, no resultaba operativo respecto a los procedimientos en curso, los que ante la inexistencia de disposición en contrario, deberían culminarse conforme a la legislación bajo cuya vigencia se hubiesen iniciado, según es regla procedimental de la que es ejemplo la contenida en la disposición transitoria de la Ley de Procedimiento Administrativo de 17 de julio de 1958, o en otro caso, siguiendo los principios de la disposición transitoria cuarta del Código Civil, por la que los interesados optasen, en el supuesto que examinásemos la anterior, ya que los Ayuntamientos interesados, no obstante la publicación de la Ley 71/1985, de 2 de abril, remitieron sus actuaciones a la Generalidad a efectos de aprobación por esta." 
Contencioso-Administrativo de la Audiencia Territorial de Santa Cruz de Tenerife de 5 de marzo de 1982, revalidando la constitucionalidad del control de legalidad gubernativo dispuesto para los casos de adhesión o separación de municipios a una / de una mancomunidad en el artículo 61 del mencionado Reglamento de Población y Demarcación Territorial (27).

Para completar estas consideraciones sobre el funcionamiento de la intervención gubernativa durante el período constitucional y hasta la aprobación de la Ley $7 / 1985$, de 2 de abril, hay que hacer somera referencia a la disolución de la mancomunidad. Sobre este extremo, aun sin un apoyo legal expreso, el Consejo de Estado no ha dudado en remitir la disolución de las mancomunidades al regimen de su constitución, en cuanto a la intervención gubernativa se refiere; en efecto, el artículo 14 del texto articulado parcial de 1977 remite a los Estatutos de las mancomunidades los casos de disolución, lo que, sin embargo, no fue obstáculo para que el alto órgano consultivo en su dictamen de 5 de noviembre de 1981, número 43.631, mantuviera que:

«... si bien los Estatutos de la mancomunidad hablaban del cumplimiento del plazo como causa de disolución de la misma, no puede decirse de tal redacción que esta disolución sea automática sin más requisitos que el acuerdo unánime de su órgano de gobierno, pues tal acuerdo no es sino el acto que inicia el procedimiento de disolución, que no puede entenderse completado en tanto no hayan informado y decidido al respecto los órganos de la Administración del Estado que intervinieron en el procedimiento de constitución. Por ello, entiende el Consejo de Estado que cuando el artículo 22.1 , a), del texto articulado parcial de la Ley $41 / 1975$, de Régimen Local, habla de disolución "por el término del plazo por el que fueron constituidas", tal disolución necesitará ser aprobada por el Consejo de Ministros, previo informe de este Consejo de Estado y a propuesta del Ministerio de Administración Territorial. Otra interpretación iría contra las competencias que en esta materia tiene el Estado (o, en su caso, las Comunidades

(27) Estos son los razonamientos de que se sirvió: "Que no puede acogerse la tesis del recurrente, de que el precepto que establece la fiscalización por la Administración de los acuerdos de los Ayuntamientos relativos a la Mancomunidad de Municipios, haya sido derogado por la Constitución, como declaró la Sentencia del Tribunal Constitucional de 2 de febrero de 1981, pues lo que indica tal Sentencia es que no puede el Gobierno denegar la aprobación por motivos de oportunidad, $y$ en tal sentido es inconstitucional ese aspecto del artículo 15.2 del Real Decreto 3046/1977, pero no el resto que le atribuye un control de legalidad, $y$ precisamente por ello, es por lo que hay que estimar vigente el procedimiento de remisión al Gobierno de los expedientes para que pueda ejercer tal control." 
Autónomas o los Entes Preautonómicos) en orden al control de legalidad de las mancomunidades intermunicipales en cuanto gestoras, no sólo de los intereses peculiares de los Municipios integrantes, sino también, obviamente, de intereses generales. Por lo demás, estas sugerencias procedimentales no merman el principio de autonomía que a las entidades territoriales atribuye el artículo 137 y concordantes de la Constitución, como ha tenido ocasión de declarar a estos efectos el Tribunal Constitucional en su sentencia de 2 de febrero de $1981 \ldots$..

\section{b') Principio de autonomía y fines de las mancomunidades}

La genérica remisión al establecimiento y desarrollo de obras, servicios y otros fines de la competencia municipal a que aludía el artículo 10.1 del Decreto que desarrolló parcialmente la Ley de Bases del Estatuto de Régimen Local ofrecía al intérprete la duda sobre la extensión de los fines atribuibles a la responsabilidad de las mancomunidades. La cuestión no se planteaba por vez primera en la época en que estas reflexiones se sitúan; sin embargo, es en ese momento cuando el Consejo de Estado, con base en el constitucional principio de autonomía, apoyó la posible recepción por parte de las mancomunidades de un extenso conjunto de competencias municipales, sin que ello, en ningún caso, pudiera suponer un vaciamiento de las responsabilidades municipales en favor de los entes interpuestos; esta posibilidad, derivada de la autonomía reconocida a los Municipios por el artículo 137 de la Constitución, encuentra un tope infranqueable en el detrimento de la propia sustantividad del Municipio y en las funciones de gobierno y administración atribuidas por la propia Constitución a los Ayuntamientos (28).

\section{c) Mancomunidades provinciales}

La aprobación de la Constitución, con su capital trascendencia en lo que a organización territorial del Estado se refiere, propició que surgieran ciertas dudas sobre la compatibilidad de las jóvenes mancomunidades provinciales, que, como se recordará, adquirieron carta de naturaleza en la Ley de Bases, número 41, de 1975 y su texto articulado parcial aprobado dos años más tarde, con el texto

(28) Vid., dictamen del Consejo de Estado de 17 de diciembre de 1981, núm. 43.749. También el de 22 de octubre de 1982, núm. 44.711, flexibiliza los fines a que pueden atender las Mancomunidades, al argumentar que éstas pueden gestionar competencias de asesoramiento (típica atribución provincial) para el ejercicio material de aquéllas que recaigan bajo responsabilidad municipal. 
constitucional, y concretamente con algunos preceptos contenidos en su título VIII. Sometidos los artículos 18 al 22 del citado texto articulado a la consideración del Tribunal Constitucional, concluyó por aceptar (sentencia de 2 de febrero de 1981) la compatibilidad de aquéllas con el texto fundamental; sus argumentos fueron éstos: es legítimo el control gubernativo sobre la constitución de mancomunidades provinciales por la posible incidencia de éstas en intereses generales ajenos a los propios de cada provincia, $y$, sobre todo, legitima su constitucionalidad el carácter sectorial, que puede convertir a las mancomunidades provinciales en instrumento adecuado para gestionar obras, servicios o actividades de interés común a diversas provincias y de su competencia (29). Lo cierto es que, pese a que el Tribunal Constitucional entendió que era viable este cauce, paralelo al recién estrenado en aquel momento de las Comunidades Autónomas, la L.R.B.R.L. omitió la regulación de este tipo de mancomunidades, y además su disposición transitoria novena previó que en el plazo máximo de un año desde la entrada en vigor de esa Ley el Gobierno dispondría la disolución de la Mancomunidad de Diputaciones de Régimen Común, lo que se produjo por Real Decreto 1145/1986, de 6 de junio.

(29) Textualmente (fundamento jurídico 17, Sentencia del Tribunal Constitucional de 2 de febrero de 1981): "En el recurso que impugnan los artículos 18 a 22, inclusive, del Texto Articulado Parcial de la Ley de Bases del Estatuto de Régimen Local, relativos a las Mancomunidades Provinciales, por entender que infringen además de los preceptos relativos al principio de autonomía (artículos 137, 140 y 141.2 de la Constitución), los artículos 143, 145 y 148.2 de la propia norma fundamental, ya que -según indican los recurrentes- la regulación de las Mancomunidades provinciales parece un contrasentido en el título VIII de la Constitución.

El recurso se fundamenta, pues, en la disconformidad de los preceptos impugnados con dos grupos de artículos de la Constitución, por lo que conviene examinarlos separadamente.

En primer lugar, respecto a los artículos 137,140 y 141,2 que se refieren al principio de autonomía, debe hacerse notar que la existencia de control se justifica precisamente por el hecho de que la constitución de la Mancomunidad provincial puede incidir en otros intereses generales distintos de los propios de cada una de las provincias que la forman.

En segundo término, respecto a los artículos 143,145 y 148 de la Constitución, no puede afirmarse a juicio de este Tribunal que los preceptos impugnados sean opuestos a la Constitución, dado el carácter sectorial de las Mancomunidades, y el hecho de que puedan existir obras, servicios o actividades de interés común para varias provincias en materia propia de su competencia, con un ámbito territorial inferior y no coincidente con el de una Comunidad Autónoma, o incluso que ésta decida encomendar a una Mancomunidad.» 
REALA-1990, núm. 248. QUINTANA LOPEZ, TOMAS. LAS MANCOMUNIDADES EN NUESTRO DEREC...

REALA-1990, núm. 248. QUINTANA LOPEZ, TOMAS. LAS MANCOMUNIDADES EN NUESTRO DEREC... 